\section{Case management}

DeAR SirS

Dr Abrahamson alerts us to the numbers of mental health professionals germinating into case managers (Psychiatric Bulletin August 1993, 17, 499). This trend is matched by a large volume of literature about the subject which is reviewed by Thornicroft (1990).

Various models of case managements have been proposed but, in its most ambitious form, the job indeed requires a multitude of skills including engagement, assessment, consultation with families, psychoeducation, crisis intervention and advocacy (Kanter, 1989). The breadth and intensity of a psychiatrist's training, and the extent of his or her knowledge about the biological, social and psychological aspects of mental illness make psychiatrists and trainees particularly well suited to the role of case manager. Indeed, if psychiatrists do not participate in case management there is a danger that we will be reduced to medication prescribers alone.

Supervision is of paramount importance to the success of case management and is often poorly addressed by its exponents. Unsupervised and unsupported case managers are at risk of becoming demoralised by working with different clients, suffering emotional over-involvement and clinical isolation.

Having had personal experience of case management and read about the roles and functions of the case manager, we still wonder what are their responsibilities, and to whom are they accountable? Will the advent of case management mean that the other remaining function of psychiatrists is to carry the legal can, despite our increasingly peripheral involvement, when the patient's management goes wrong? To avoid these problems, and prevent our own marginalisation, consultant psychiatrists must surely continue to supervise the other case managers within the multidisciplinary team setting.

Several studies have suggested that case management improves the outcome for the chronic mentally ill (Solomon, 1992). Psychiatrists are indeed well advised to participate in the debates surrounding case management and its implementation. It may well make a useful contribution to the community based psychiatric care of the 1990s.

ROBERT Chaplin

Royal Park Hospital

Parkville Melbourne

Victoria 3052

Australia

\section{References}

KANTER, J. (1989) Clinical case management: definition, principles, components. Hospital and Community Psychiatry, 40, 361-368.
Solomon, P. (1992) The efficacy of case management services for severely mentally disabled clients. Community Mental Health Journal, 28, 163-180.

ThORNICROFT, G. (1990) Case managers for the mentally ill. Social Psychiatry and Psychiatric Epidemiology, 25, 141-143.

\section{Resuscitation skills of psychiatric trainees}

DeAR SIRS

In their article (Psychiatric Bulletin, August 1993, 17, 489-491) Kosky and Spearpoint highlight serious deficiencies in the resuscitation skills of psychiatric trainees-findings which are compatible with my own experiences in psychiatry.

Their results are unsurprising. Trainees are rarely called upon to perform resuscitation. Any resuscitation skills that they had on entering psychiatric training rapidly decline with lack of practice and are only maintained with regular rehearsal - a facility not available to most trainees.

The guidelines for the management of cardiac arrest are periodically revised. Without regular retraining it is unlikely that a trainee will remain up to date even if their basic life support skills are intact.

Adequate assistance from trained nursing staff is vital as a trainee managing a cardiac arrest is likely to be the only doctor present but most psychiatric nurses have done little general nursing and feel inadequately trained in assisting at resuscitation.

Basic life support skills are expected of any doctor. However, advanced resuscitation skills (defibrillation, intubation, gaining central venous access etc) can only be expected when regular training in and practice of such techniques is available. No psychiatric hospital that I have worked in has provided this. In three years as a trainee I have had only two brief refresher sessions in basic cardio-pulmonary resuscitation.

As Kosky and Spearpoint note, poor resuscitation skills are not restricted to psychiatrists. David \& Prior-Willeard (1993) examined 30 MRCP Part II candidates and found that 29 had inadequate basic life support skills and lack of knowledge of current guidelines. Nineteen of these candidates went on to pass the MRCP. The authors conclude that the time has come for regular, compulsory training in resuscitation.

Hospitals should decide what level of competence they expect in resuscitation and then provide appropriate regular training for both medical and nursing staff.

\section{The Elms Clinic}

J. D. D. LAIDLAW

Banbury, Oxfordshire 